\title{
Development of Scale of Critical Factors for China's Tourism Industry in E-commerce Environment
}

\author{
Yingmei Wei*, Runsheng Fang and Yuqiang Feng \\ School of Management, Harbin Institute of Technology, Haerbin, China \\ Zhongyuan University of Technology, Zhengzhou, Henan \\ Henan University of Economics and Law, Zhengzhou, China \\ School of Management, Harbin Institute of Technology, Haerbin, Heilongjiang \\ 649070917@qq.com*
}

\begin{abstract}
Considering the tourism industry technologies in e-commerce environment and other basic conditions are perfect, but the profit is still very little. In this study, a draft questionnaire scale is designed based on critical success factors (CSF) combined with some theories and the opinions of 23 senior managers in tourism enterprise who constructed the judgment matrix introducing innovative and legalization modules. The approaches, analytic hierarchy process (AHP), group eigenvalue method (GEM) and corrected item-total correlation (CITC), are respectively used to test. After removing those bad items on the basis of comprehensive output results while comparing three test approaches, the scale is modified to finalize the formal survey questionnaire to complete the preliminary work of research on tourist industry innovation and services spiral development in e-commerce environment. The research shows that there is a big gap between the primary concern of Chinese enterprises and the sustainable tourism economy in the world.
\end{abstract}

Keywords: E-commerce environment, Chinese tourism industry, scale development, purify questions, Service Spiral Development

\section{Introduction}

Many tourism enterprises in China have developed a new marketing channel through selfsupporting or third party e-commerce website $[1,2]$, and consumers have also gradually recognized and accepted consumption pattern of e-commerce. The supply of Chinese tourism e-commerce is more than the demand. However, in light of easy imitation and high alternative of tourism products [3], the previous researches merely focus on researchers' self-deduction, having certain limitations and it is difficult to find a winning method. Therefore, most ecommerce platforms don't have expanding functions and fully achieving enterprise integration, providing diversified and personalized service, improving credibility and security system construction, and speeding up cultivation of compound talents [4]. That is to say, to those outside, the enterprise information system itself has no communication with ecommerce; let alone tourism industry connects and communicates with relevant tourism industries such as transportation, tourism commodity product and catering industry on network platform, and synergy among industries has not been improved; network interactivity with consumers is only limited in one-sided information release and simple tour communication. To those inside, it does not improve the management level and forecast market and pre-estimate new products through reality; the following practices are little help: sectors in the company cooperate with each other and enterprise culture and employee 
cohesion gradually strengthens; there is a lack of building client information database, setting up special service for big customers and completing deep digging of Customer Relationship Management system (CRM). Tourism industry in e-commerce environment is still in the loose condition for enterprises' self-governing and mutual independence.

This study concentrates on the problems incurred in tourism industry in e-commerce environment and related researches, and from the perspective of resource-based view (RBV) (Wernerfelt, 1984) in e-commerce environment, emphasizes critical success factors (CSF) (William, 1970) recognition of e-commerce profit in tourism industry. According to the existing problems and after consulting a large of literature review, we choose some theoretical modeling, which are strategic service management paradigm (SSMP), five forces model of industry competition structure (Porter, 1979), returns on quality (ROQ) (Rust et al., 1995, also known as service quality earnings) and unified theory of acceptance and use of technology (UTAUT) (Venkatesh, 2003). After discussing with the managers of the Tourism Bureau, tourism enterprises and relative enterprises managers, the research constructs four dimensions including enterprise performance, innovation of products and service, situation of resource allocation and service performance with 19 factors to affect collection of tourism cooperation in e-commerce environment, and designs the questionnaire draft of critical profitability factors. The study compares the collected data and recognizes critical success factors with analytic hierarchy process (AHP), group eigenvalue method (GEM) and corrected item-total correlation (CITC) respectively. Objective of the research is to understand and grasp the actual influence factors of tourism industry after expanding ecommerce channel, as well as to find the main profit driving force from innovation ability, government resource and natural resource conditions and relevant development and other aspects in order to easily perform subsequent researches such as factor analysis and upward screw structure of service industry. And to promote the training and development needs by improving the quality of services, in order to achieve a balance between supply and demand of electronic tourism market.

\section{Literature Review}

The core of the tourism industry in e-commerce environment is profit. Through literatures review, we can find that relevant researches on current tourism e-commerce profit model mostly focus on the perspective of management (Timmers, 1998; Linder \& Cantrel, 2000; Weill \& Vitale, 2001). Relevant researches in China can be roughly divided into four parts: firstly, adopt the element combination comparison profit pattern of " profit point + profit source+ profit leverage + profit barrier" in e-commerce[5];secondly, it is brand advantage, emphasizing synergy and cooperative competency between tourism e-commerce and other sectors, highlighting unique brand advantage of tourism e-commerce [6]; thirdly, it is difference advantage, and the scholars design characteristic advantage to fill the part of which other tourism behavior models are short [7]; finally, tourism e-commerce is analyzed by strengths weakness opportunity threats(SWTO analysis) in marketing. (Cao Huilin, 2006; Li Yongqin, 2009). There are also many researches on tourism industry profitability factors of ecommerce as well. These researches can also be divided into pre-tourism behavior (Zhu Zhen and so on, 2008; Wang Zhongfu, 2011; Gong Ye, 2012), the process of tourism behavior( Samuel, 2009) and post-tourism behavior (Dolnicar, 2004; Chen Juan and so on, 2005) according to time phases, and they have analyzed profitability factors influencing tourism ecommerce respectively. On the basis of consumer satisfaction mainstream pattern, we have extended and expanded research on the basis of "the pattern of expectation and actual performance" proposed by Oliver, "the pattern of consumer demand satisfaction" Westbrook 
has offered, "the comparison pattern of consumer consumption experiences" presented by Woodruff, and Consumer Satisfaction Barometers (SCCB, ECSI, ACST) in Sweden and other countries. (Anderson, 1993 ; Cronin \&Taylor, 1992; Petrick \& Morais, 2001; Gao Chongyan and soon, 2007; John \& Matthew, 2011). By induction, the research finds that relevant researches of Chinese tourism industry profit pattern in e-commerce environment have several limitations as follows:

Firstly, elements affecting profitability are not comprehensive. Through literature review, the author can see that e-commerce research is more comprehensive, and it has spanned many disciplines including computer, internet technology, trade, service and management $[8,9]$. However it is the following problems that lead to the non-objective research results: (1Lack of natural resource influence research: Song (2007) has pointed out that there are more than one hundred and two forward or backward industries directly connected with tourism industry, among which objective reality of natural resource and regional culture is the root and basis of tourism industry (Wang Meng, 2012). Limited ecological tourism compensation and culture creative tourism research has been carried out in accordance with tourism ecommerce (Feng Fei, 2004; Liu Xiao, 2010; Taiwan Industrial Bureau). But research direction is concentrated on the perspective of competition judgment [10], and it has little research interaction with profit pattern.(2) Lack of legal research: the so-called legalization refers to behavior and activities conforming to laws and regulations of the country (Ying Nanshu, 2008). Only if activities are confirmed by government, other sectors and consumers can economic activities have broad development space. We find that micro-research is very detailed from literature analysis, while macro legal environment research (from the perspective of government and industry and so on) is relatively rare [11,12]. Only Wei (2011) has stressed the essential government role in e-commerce. Rappa (2006) has presented his opinions from the perspective of macro-industry, and e-commerce has showed how enterprises make money by describing how enterprises find their positions in industry value chain. (3) Difference between researches and actual operation: Many scholars have studied complicated profit structure (Rollins, 1997; Gursoy et al., 2007; Weaver \& Lawton, 2001). In economics field, there are lots of research and development accessory methods, such as RBV, grey system theory, J2EE, ant clustering algorithm and SOA software and other development methods (Statia, 2011; Liu Xianfeng, 2013), but it is very difficult to put those research results into practice[13], so tourism enterprises are not capable of improving company situation according to research results.

It is not explicit that elements affecting profitability in scale or CSFs of tourism in ecommerce environment. According to development stage of Nolan pattern[14], development of information system in e-commerce environment needs to experience four stages, and the relevant research confirms that the first and the second stages are better than the other two stages. Setup stage, the stage of technology specification, which includes the requirements of implementing necessary technology and hardware facilities in e-commerce(Jason G,2010; Chen Shan, 2011); and Spreading stage, the stage of behavior regulation, refers to cognition and accepts stage of customers and cooperators $[15,16]$. These two parts of research are more comprehensive and creative. But in those two stages, control stage (innovative stage, innovation is the power of profit) [17] and integration stage (personalized service stage, where resource is highly concentrated and efficiently used), e-commerce has brought homogeneity to information and service as well as eliminated information difference. Even because of homogeneity of service objects, the gap in competitive advantage is narrowing, and innovation has become the channel of increasing profit [18]. Therefore, the research participants from enterprises in the design segment of the survey will avoid sensitive issues, 
causing questionnaire not to reflect real condition (Tan Sheng, 2003; Tang Yongling, 2012); Or they might avoid some core problems even give a false reply, making the enterprise information management or service features not be imitated to protect their core competence and original competitive edge (Chen Hongzhuan, 2004), which makes the questionnaire results have very limited reference value. Thus the researches design a scale to find the difference focus of theory and reality.

Although relative perspectives are different, they are mutual independent and cannot reflect existing problems completely and objectively alone. E-commerce environment and tourism industry is a cross field of two different disciplines on the surface, but actually it has a wide cross part, involving various fields including internal resource integration, external resource coordination and environment policy support and consumer awareness and other fields. Any fluctuating factors of these will affect the enterprise's profitability. However, at present the integrated and overall research on tourism industry in e-commerce environment has not been paid attention, even there is no empirical research to test how to improve gradually service quality between economic rationality and regulation rationality in tourism industry of e-commerce environment, and dig spiral motion law of service quality. Therefore, this research should design a scale, bring the service influence elements of natural resource, government factor, creative drive and cooperation ability into the dimensions, expecting to achieve more objective reality and be prepared for relevant empirical research launched later.

\section{Methodology}

\subsection{Critical Indicators Design}

CSF is commonly used in the field of information system research. Prior to the implementation of plans by tourist enterprises in e-commerce environment, it is significant to have a full understanding of CSF in e-commerce environment for improving the success rate of operation of the project. According to the problems sorted out from literature, 4 criterion layers, 19 indicators judgment matrixes are defined firstly after discussion with and modification by related experts and the detailed analysis is as below:

The five-force model of industry competition structure is a theory for enterprises to achieve competitive advantage and also the most widely applied theory in research on industry profitability [19], which can effectively analyze the business environment. These five forces derive from the accession of potential competitors, alternatives, bargaining power of buyers, bargaining power of suppliers and competitiveness of competitors within the industry. Similarly, tourism e-commerce enterprise shall also take a full consideration of these forces inside and outside if it wants to make a profit, since any variations will cause fluctuations in the enterprise. Therefore such indicators as customer resource, government resource, cooperation ability, market orientation, enterprise strategy and innovation ability, etc. are set in resource allocation in this scale design.

Hawkins et al. (1995) pointed out that the enterprises get a new customer which cost is five times keeping an old customer. And each 100 satisfied customer will bring about at least 25 new customers. It is evident that customer resource is significant to the enterprises, while the willingness of customers to use e-commerce is the key to profitability. In UTAUT theory [20], the influential factors are divided into four aspects: use expectation, performance expectation, community impact, and facilitating conditions. The theory integrated with the willingness of users to use information system. And other factors, such as gender, age, experience and willingness to use, are listed as the base. The key of tourism industry in ecommerce environment lies in e-commerce, related to whether consumers are willing to 
choose e-commerce channels to make reservations before travel, consult and purchase, etc.; as well as change arrangement in travel; negotiate on service content, evaluate after travel; and offer opinions and suggestions to potential travelers and other matters. Four factors included in UTAUT will be directly introduced in the scale design.

Yuhei \& Seoki (2011) and John \& Matthew (2011) found that service quality had positive influence on enterprise performance. Tourism e-commerce also requires a high level of quality of service. ROQ [21] will be adopted which holds that quality is a kind of investment, and improvement on quality shall follow the economic principle. However, the investment on improvement of quality is likely excess, and not all of the quality of investment is worth. Only innovation on service will gain competitive advantages. The case of Apple confirms that innovative services will bring surprises in the senses, thus obtaining high profits. Innovation of services can be measured from three aspects: frequency, input and resource. In consideration of the significance of service in tourism e-commerce, in this scale, the service quality theory will be integrated into two destination layers: service performance and product and service innovation, and the characteristic of travel and tourism e-commerce as service industry is taken into full consideration.

SSMP is a classical theory in the profitability process of service industry [22]. It claims that profitability process of the enterprise is a transfer process started from service improvement to the quality of service, and then to customer performance. Horng and Tsai (2010) indicated that government tourism websites' framework for promoting culinary included tourism cuisine and food culture, featured foods and recipes, table manners, culinary tourism, restaurant certification, restaurant guide and twenty-five dimensions after comparing six Asia government countries using content analysis instrument [23]. The tourism industry in e-commerce environment is still vested in the service industry, and its profitability, profitability stability and profitability growth property will not only be affected by the five forces but also fluctuate due to the difference in quality of service provided. The overall profitability of the enterprise should fully consider the effect from the inside and outside.

The detailed indicator layer is worked out after four criterion layers are defined, see Table 1. The scale is designed taking consideration the principle of "profit point + profit source+ profit leverage + profit barrier", hence scale can also be illustrated by this principle, see Table 2.

\subsection{Identification Method of Critical Indicators}

Commonly methods to identify critical success factors are AHP, GEM, least-square method (LMS), Delphi method and dendrogram, etc. The first two methods compared to other methods have the ability to deal with decision-making factors qualitatively and quantitatively, which is systematic, flexible, simple and easy to achieve. But GEM and AHP have their own strengths and weaknesses. Both methods are used for more scientific judgment in this research:

AHP proposed by Saaty is a thinking method of decision-making essentially, breaking a complex problem up into sub-problems composed of the same elements, and finding out the relationship between them, is a practical approach for decision making. It presents digitally combining sensory perception, experience and mathematical methods. By simply changing the mathematical matrix model, standardize the decision-making process. The whole process of decomposition, judgment and integration in the process of decision-making is reflected. Judge on whether the matrix is acceptable with $\mathrm{CR}<0.1$; if $\mathrm{CR}>0.1$, a new judgment matrix shall be established. 
Table 1. Assessment Indicator System of Critical Factors for Chinese Tourism Industry in e-commerce Environment

\begin{tabular}{|c|c|c|c|}
\hline Dimensions & Level indicators & The secondary indicators & Sources \\
\hline \multirow{3}{*}{$\begin{array}{c}\text { enterprise } \\
\text { performance } \\
\text { a }\end{array}$} & profitability a1 & $\begin{array}{l}\text { Corporate promts, emproyee dements, stock } \\
\text { appreciation, extension and development of }\end{array}$ & Leimeister et al.(2004) \\
\hline & $\begin{array}{l}\text { growth property } \\
\text { a2 }\end{array}$ & debt ratio, capital chain, good capital turnover rate & Palmer(2002) \\
\hline & stability a3 & $\begin{array}{l}\text { good reputation and fame, potential to operate, } \\
\text { expanded awareness }\end{array}$ & Leimeister et al.(2004) \\
\hline \multirow{3}{*}{$\begin{array}{l}\text { product and } \\
\text { service } \\
\text { innovation } b\end{array}$} & $\begin{array}{l}\text { Innovation input } \\
\text { b1 }\end{array}$ & $\begin{array}{l}\text { total investment in new technology of website, total } \\
\text { funding in research and development of tourism } \\
\text { new products }\end{array}$ & $\begin{array}{l}\text { Deng Yihua et al. (2002) } \\
\text { Christensen (1995) }\end{array}$ \\
\hline & $\begin{array}{l}\text { Innovation } \\
\text { frequency b2 }\end{array}$ & $\begin{array}{l}\text { period of new technology research and } \\
\text { development, period for research and development } \\
\text { of new tourism products }\end{array}$ & Wang et al. (2004) \\
\hline & $\begin{array}{l}\text { Innovation } \\
\text { resource b3 }\end{array}$ & $\begin{array}{l}\text { Introduction and employment of highly educated } \\
\text { personnel, senior and professionals }\end{array}$ & Christensen（1995） \\
\hline \multirow{8}{*}{$\begin{array}{l}\text { Resource } \\
\text { allocation c }\end{array}$} & $\begin{array}{l}\text { Natural resources } \\
\text { c1 }\end{array}$ & $\begin{array}{l}\text { Environmental impact, ecological compensation, } \\
\text { customs and culture, public security }\end{array}$ & Wang Zhongfu et al. (2011) \\
\hline & $\begin{array}{l}\text { Customer } \\
\text { resources c2 }\end{array}$ & Emphasis on customer management & $\begin{array}{l}\text { Zhao Jing et al. (2006) } \\
\text { Pettersson et al.(2011) }\end{array}$ \\
\hline & $\begin{array}{l}\text { Governmental } \\
\text { resources c3 }\end{array}$ & $\begin{array}{l}\text { Promoting the protection and restoration of tourism } \\
\text { resources, tourism supporting public utilities, city } \\
\text { image promotion, government support }\end{array}$ & $\begin{array}{l}\text { Zhu Dajian et al. (2011) } \\
\text { Wei Yingmei et al. (2014) }\end{array}$ \\
\hline & $\begin{array}{l}\text { Cooperation } \\
\text { ability c4 }\end{array}$ & $\begin{array}{l}\text { Cooperation process, cooperative security, } \\
\text { information sharing demand }\end{array}$ & Li Suicheng et al. (2008) \\
\hline & $\begin{array}{l}\text { Information } \\
\text { system resource c5 }\end{array}$ & $\begin{array}{l}\text { Meeting the basic requirements (reliability, security, } \\
\text { openness, advancement, scalability, usability, } \\
\text { integration),Information sharing capacity } \\
\text { (information sharing, order sharing, customer } \\
\text { feedback sharing), senior leader support }\end{array}$ & $\begin{array}{l}\text { Negash et al.(2003) } \\
\text { GB/T26360-2010(2011) } \\
\text { Tsaia et al.(2005) }\end{array}$ \\
\hline & Internal staff c6 & $\begin{array}{l}\text { Incentive systems, IT skills and expertise, focusing } \\
\text { on training, corporate culture }\end{array}$ & $\begin{array}{l}\text { Devaraj \& Kohli (2003) } \\
\text { Yang jianzheng et al.(2010) }\end{array}$ \\
\hline & $\begin{array}{l}\text { Market orientation } \\
\text { c7 }\end{array}$ & $\begin{array}{l}\text { Market competition, industry informatization level, } \\
\text { international group access }\end{array}$ & Negash et al.(2003) \\
\hline & $\begin{array}{l}\text { Enterprise strategy } \\
\text { c8 }\end{array}$ & $\begin{array}{l}\text { Incorporating website operation into long-term } \\
\text { strategy of enterprise, financing capacity, project } \\
\text { management system }\end{array}$ & Zhao Jing et al. (2006) \\
\hline \multirow{5}{*}{$\begin{array}{c}\text { Service } \\
\text { performance d }\end{array}$} & $\begin{array}{l}\text { Use expectation } \\
\text { d1 }\end{array}$ & $\begin{array}{l}\text { Willingness to use (supporting personalized } \\
\text { services), }\end{array}$ & Delone\& McLean(2003) \\
\hline & $\begin{array}{l}\text { Performance } \\
\text { expectation } \mathrm{d} 2\end{array}$ & $\begin{array}{l}\text { The degree of help of using system and enjoying } \\
\text { services to oneself in personal opinions }\end{array}$ & $\begin{array}{l}\mathrm{Wu}(2004) \\
\text { Ahearne et al. (2008) }\end{array}$ \\
\hline & $\begin{array}{l}\text { Community } \\
\text { impact d3 }\end{array}$ & Subjective norm, social factor and public image & $\begin{array}{l}\text { Dayal et al.(1999) } \\
\text { Yu (2010) }\end{array}$ \\
\hline & $\begin{array}{l}\text { Facilitating } \\
\text { conditions d4 }\end{array}$ & 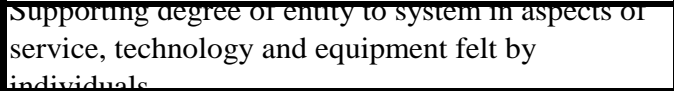 & Andrew\&Camille(2013) \\
\hline & $\begin{array}{l}\text { Related industry } \\
\text { service d5 }\end{array}$ & products developed by the company (hotel, & Delone\&McLean(2003) \\
\hline
\end{tabular}


GEM was proposed by Mr. Qiu Yuanhua from Beijing University of Aeronautics and Astronautics (BUAA) in 1996. Compared with AHP, it overcomes the inconsistency of judgment matrix. The assessed judgment and decision on multiple targets is made by group experts. The ideal judgment of expert is calculated through matrix transformation. Multiple assessed targets can be sorted by the score. The basic steps: experts will give a mark for the assessed targets firstly, then the research gets matrix $\mathrm{T}$ through multiplied the transposed matrix and itself, and the eigenvector corresponding to the largest eigenvalue of $\mathrm{T}$ is the required optimal decision.

Table 2. Other Theoretical Illustrations of Scale

\begin{tabular}{r|l}
\hline $\begin{array}{l}\text { Principle of "profit point+ profit } \\
\text { source+ profit leverage + profit } \\
\text { barrier" }\end{array}$ & Criterion layer of scale \\
\hline Profit point & Natural resources, customer resources \\
\hline Profit target & $\begin{array}{l}\text { Use expectations, performance expectations, } \\
\text { community impact and facilitating conditions of } \\
\text { customers to e-commerce environment }\end{array}$ \\
\hline Profit source & $\begin{array}{l}\text { Related industry services, cooperation capacity, } \\
\text { information system source, innovation capacity }\end{array}$ \\
\hline Profit barrier & $\begin{array}{l}\text { Market orientation, governmental resources, } \\
\text { natural resources, enterprise strategy, innovation } \\
\text { capability, internal staff }\end{array}$ \\
\hline
\end{tabular}

From the point of principle and characteristics of methods, GEM needs not to calculate the weight of comparative judgment matrix of either assessed target, and the problem of inconsistent judgment matrix in AHP method at times is overcome. As a result, GEM method is simpler than AHP method. However, ambiguous structure and over-abstraction may exist in GEM method. Therefore, in this study, AHP method and GEM method are both used to test the same group of data respectively, in which way the scientific problem solving process of hierarchical structure establishment in AHP method is retained while direct pointing by experts in GEM method is adopted to assist judgment. In the meantime of comparing output results of two methods, the indicator weights of all criterion layers can be comprehensively judged.

As the follow-up study will carry out factor analysis, CITC reliability test, KMO measure of sampling and Bartlett test of sphercity. Firstly, test the reliability and stability of questionnaire. Cronbach's $\alpha$ (values above 0.7 will be deemed as acceptable) will be used in the study to test the consistency degree of measure. Then, KMO measure of sampling (values above 0.7 will be deemed as acceptable) and Bartlett test of sphercity verify whether the test result reflects the internal structure of concept and proposition. On the premise of meeting the above conditions, the theory holds that the coefficient of total correlation shall be deleted when it is low, which means the item shall be deleted when CITC of the indicator is lower than 0.5 . It is also considered that the coefficient of total correlation reaches 0.3 can also reach the level of research.

To sum up, in this study, the output results of AHP, GEM and CITC will be combined in the comprehensive judgment. After deleted the low weight items in the level indicators layer, we accept the end whenver the coefficient of total correlation after modification is lower than 0.3 and $\alpha$ will be increased after the item is deleted. 


\subsection{Research Methodology and Research Process}

In order to truly reflect the idea of tourism enterprises in e-commerce environment, 16 tourism enterprises or enterprises that are closely linked with tourism e-commerce were invited (see Table 3), among which there are 9 enterprises established for more than 10 years; 2 enterprises engaged in e-commerce businesses for more than 8 years, and the rest enterprises have the experience in e-commerce operation for 1-5 year(s); 12 enterprises have a total annual sales revenue for over one million yuan. 23 persons in charge of departments of these enterprises were invited to construct the judgment matrix. In these experts, there are 15 middle managements. The invited experts not only have rich experience in e-commerce operation but also are familiar with the operation mechanism in tourism enterprise, or have engaged in related management in tourism industry for many years, hence they can present compellent judgments. In this study, the draft questionnaire scale is made after repeated negotiation and modification with experts for a period of more than 4 months.

Firstly, 6 criterion layers' matrix in the initial design of first research were sent to the experts who were required to evaluate with Likter 5-point scale (very important (5 points), more important (4 points), generally important ( 3 points), less important ( 2 points) and not important (1 point) according to the situation of enterprises. On the basis of the results, statistics on range, standard deviation and mean value of enterprises was made. Parts of the experts were invited to discuss and present their opinions on tourism industry in e-commerce environment by the way of QQ group chat. Then, the feedback on the first statistical results and scale in the second round was sent to the experts who were asked to compare the indicators at the level indicator layer between either of them and write down the corresponding comparative matrix. Finally, 4 criterion layers and 19 destination layers were defined for the questionnaire in the first round.

Table 3. List of Selected Enterprises

\begin{tabular}{|c|c|}
\hline Dianping(www.dianping.com) & China Comfort Travel Henan Co., Ltd. \\
\hline Hanhai Information Technology (Shanghai ) Co., Ltd. & Shenzhen Comfort Travel Service Co., Ltd. \\
\hline $\begin{array}{r}\text { Joyu International Tourism Operation Group } \\
\text { (lvmama.com) }\end{array}$ & North Sea Global International Travel Service \\
\hline Henan Tourist Administration & Guangxi Business International Travel Service \\
\hline Zhengzhou Tourism College Travel Agency & Yuchai International Travel Co., Ltd. \\
\hline Industrial Bank Co.,LTD. & $\begin{array}{l}\text { Guohua Holiday (Beijing) Travel Service Co., Ltd. } \\
\text { Henan Branch }\end{array}$ \\
\hline Hefei Tourist Distributing Center Co., Ltd. & $\begin{array}{l}\text { Hainan Leyou International Travel Service Co., Ltd } \\
\text { Haikou Branch }\end{array}$ \\
\hline Beijing Dong International Travel Agency Co., Ltd. & $\begin{array}{l}\text { Sanya Chunqiu International Travel Agency Co., } \\
\text { Ltd. }\end{array}$ \\
\hline
\end{tabular}

The questionnaire employs Likter 9-point interval scale to measure, the items are "very important ( 9 points), more important ( 7 points), generally important (5 points), less important ( 3 points) and not important ( 1 point)". 8 is the importance degree between 9 and 7, 6, 4 and 2 can be done as the same manner. When marking the items, the larger the figure is, the higher the importance degree of criterion layer will be.

In AHP analysis, the establishment of judgment matrix shall be with the help of delphi method and Matlab software to make weight calculation to all criterion layers. Excel is used in GEM judgment, while SPSS 19.0 is employed in reliability and validity analysis. 


\section{Optimization Procedure of Questionnaire Scale}

A pre-test is carried out through GEM, AHP and CITC. After removing those with smaller weight and low statistically correlated survey questions, the questionnaire is modified and cleaned to finalize the formal survey questionnaire.

\subsection{Initial Analysis on Critical Factors}

The first output is in Table 4. The number of CSF depends on the relative weight and total number of variables in the study. In generally, variables with the weight greater than $0.1 \mathrm{can}$ be retained as critical factors. Since criterion layer of this scale is relatively more, it is unable to use a specific value as a standard. Pairwise comparison is used here to take the criterion with lower weight as non-critical factors at the same destination layer, and make a mark of deleting (marked $*$ in Table 4). And in AHP method, if CI, CR values are still smaller than 0.1 after deleting, the draft is proved have been improved.

In reliability and validity output judgment, the criterion layers with CITC lower than 0.3 is to be deleted (marked * in Table 4). If reliability coefficient Cronbach`s $\alpha, \mathrm{KMO}$ measure of sampling and Bartlett test of sphercity output values are increased after deleting, then delete. In the comprehensive judgment, combine with the conclusion of three inspections. And if three test results at this criterion layer have the deleted mark, then confirm to delete.

As shown in Table 4, comparing output data of AHP and CITC tests, the judgment matrix is useful if CR value of AHP is lower than 0.1. Where output values of CITC Cronbach's $\alpha$ and Bartlett test of sphercity meet the basic requirements. The value of KMO measure is low due to fewer samples.

(1) From 19 output values of indicator layers analyzed by AHP, "stability" in the dimensions layer "enterprise performance" is only 0.0510, relatively lower than other indicators at the same destination layer, marked to be deleted. Similarly, "innovation resources," in "product and service innovation", "market orientation" and "enterprise strategy" in "resource allocation", and "related industry services" in "service performance" are lower than other indicators at the same destination layer, marked to be deleted. After deleted test, CR value is still smaller than 0.1 (see Table 5), which proved that primary judgment on deleting is valid.

(2) From output results of GEM, the criterion indictors with lower weight at each destination layer are the same with outputs of AHP, hence "stability", "innovation resources", "market orientation", "enterprise strategy" and "related industry service" are marked to be deleted accordingly.

(3) From the output results of CITC, indicators lower than 0.3 are "growth property", "innovation resources", "natural resources", "customer resources", "internal staff", "market orientation", "enterprise strategy", "use expectation" and "related industry service", which are marked to be deleted.

\subsection{Purification Analysis on Questionnaire Scale}

Delete the criterion indicators marked "*" among the outputs of three tests in Table 4: "innovation resources", "market orientation", "enterprise strategy" and "related industry service". If CR value in AHP, CITC Cronbach's $\alpha$ and KMO measure of sampling values are still within the acceptable range after deleted, then these 4 items are confirmed to be deleted. Since "stability" in "enterprise performance" has a low weight, although its CITC is higher than 0.3, the output values of Cronbach's $\alpha$ and Bartlett test of sphercity are acceptable after it is deleted, so confirm to delete it. In addition, for 4 high-weight indicators in output of AHP 
and GEM with CITC outputs lower than 0.3 namely "growth property", "natural resources", "customer resources" and "use expectation", the CITC output value and Cronbach"s $\alpha$ are not obviously improved after they are deleted, so do not delete.

Table 4. Test Data for Scale of Critical Factors on Tourism in e-commerce Environment

\begin{tabular}{|c|c|c|c|c|c|}
\hline \multicolumn{2}{|c|}{ Calculating methods } & \multirow{2}{*}{$\begin{array}{c}\text { AHP } \\
\text { Weight values }\end{array}$} & \multirow{2}{*}{$\begin{array}{c}\text { GEM } \\
\begin{array}{l}\text { Weight } \\
\text { values }\end{array}\end{array}$} & \multicolumn{2}{|c|}{ CITC } \\
\hline Dimensions & Level indicators & & & $\begin{array}{l}\text { Corrected } \\
\text { Item-Total } \\
\text { Correlation }\end{array}$ & $\begin{array}{c}\text { Cronbach } \\
\text { 's Alpha if } \\
\text { Item } \\
\text { Deleted } \\
\end{array}$ \\
\hline \multirow{3}{*}{$\begin{array}{c}\text { Enterprise } \\
\text { performance }\end{array}$} & Profitability & 0.0594 & 0.0594 & 0.401 & 0.686 \\
\hline & Growth property & 0.0647 & 0.0643 & $0.230^{*}$ & 0.702 \\
\hline & Stability & $0.0510^{*}$ & $0.0511 *$ & 0.311 & 0.694 \\
\hline \multirow{3}{*}{$\begin{array}{l}\text { Product and } \\
\text { service } \\
\text { innovation }\end{array}$} & Innovation input & 0.0535 & 0.0538 & 0.640 & 0.659 \\
\hline & Innovation frequency & 0.0499 & 0.0500 & 0.438 & 0.685 \\
\hline & Innovation resource & $0.0426^{*}$ & $0.0426^{*}$ & $0.229 *$ & 0.702 \\
\hline \multirow{8}{*}{$\begin{array}{l}\text { Resource } \\
\text { allocation }\end{array}$} & Natural resources & 0.0521 & 0.0522 & $0.141^{*}$ & 0.722 \\
\hline & Customer resources & 0.0630 & 0.0627 & $0.192^{*}$ & 0.704 \\
\hline & Governmental resources & 0.0478 & 0.0483 & 0.482 & 0.673 \\
\hline & Cooperation capacity & 0.0577 & 0.0577 & 0.483 & 0.683 \\
\hline & Information system resources & 0.0545 & 0.0547 & 0.461 & 0.678 \\
\hline & Internal staff & 0.0566 & 0.0565 & $0.151^{*}$ & 0.708 \\
\hline & Market orientation & $0.0450 *$ & $0.0447 *$ & $-0.041^{*}$ & 0.727 \\
\hline & Enterprise strategy & $0.0436^{*}$ & $0.0432 *$ & $-0.246^{*}$ & 0.747 \\
\hline \multirow{5}{*}{$\begin{array}{c}\text { Service } \\
\text { performance }\end{array}$} & Use expectation & 0.0584 & 0.0582 & $0.291 *$ & 0.703 \\
\hline & Performance expectation & 0.0577 & 0.0576 & 0.366 & 0.691 \\
\hline & Community influence & 0.0521 & 0.0523 & 0.395 & 0.685 \\
\hline & Facilitating conditions & 0.0552 & 0.0553 & 0.517 & 0.680 \\
\hline & Related industry services & $0.0352^{*}$ & $0.0354 *$ & $0.290^{*}$ & 0.693 \\
\hline \multicolumn{2}{|c|}{ Other reference indicators } & $\begin{array}{l}\mathrm{CI}=0.000001 \\
\mathrm{CR}=0.000000 \\
6\end{array}$ & & \multicolumn{2}{|c|}{$\begin{array}{l}\text { Reliability (Cronbach`s } \alpha \text { ) } \\
\text { KMO measure } 0.286 \\
\text { Bartlett test of sphercity sig. } \\
0.000\end{array}$} \\
\hline
\end{tabular}

* items to be deleted.

Finally there are 14 criterion indicators left. Then tested by AHP and GEM, the output result meets the requirements, see Table 5. In CITC test, there are still 2 indicators lower than 0.3 , try to delete again and find that Cronbach's $\alpha$ and KMP measure of sampling value are not significantly improved. In consideration that the weight proportion of the destination layer where it lies is larger, then retain it. 


\section{Finding}

\subsection{Introduction of Critical Profitability Factors for China's Tourism Industry in e- commerce Environment}

Accompanying GDP of China has exceed 8\% since 1999, the residents consumption ability has greatly enhanced. Luxury goods, consumable type products and entertainment products have a large number of demands, which means the tourism has also increased rapidly. Vast natural and historical cultural tourist attractions have been developed and transformed for a long period, though other facilities are still blank, such as infrastructure constructing, personnel training and waste managing. But still the tourism enterprises have made a lot of profit under the imperfect circumstances with little effort and adjustment. And they pay more attention to counting the money than protecting natural, repairing monuments, improving management and strengthening supervision, all the work to improving the quality of products and services.

\section{Table 5. Purification Data for Scale of Critical Success Factors in e-commerce Environment}

\begin{tabular}{|c|c|c|c|c|c|}
\hline \multicolumn{2}{|c|}{ Calculating methods } & \multirow{2}{*}{$\begin{array}{c}\text { AHP } \\
\text { Weight values }\end{array}$} & \multirow{2}{*}{$\begin{array}{c}\text { GEM } \\
\begin{array}{l}\text { Weight } \\
\text { values }\end{array}\end{array}$} & \multicolumn{2}{|c|}{ CITC } \\
\hline Dimensions & Level indicators & & & $\begin{array}{l}\text { Corrected } \\
\text { Item-Total } \\
\text { Correlation }\end{array}$ & $\begin{array}{l}\text { Cronbach's } \\
\text { Alpha if Item } \\
\text { Deleted }\end{array}$ \\
\hline \multirow{2}{*}{$\begin{array}{l}\text { Enterprise } \\
\text { performance }\end{array}$} & Profitability & 0.0773 & 0.0772 & 0.467 & 0.763 \\
\hline & Stability & 0.0663 & 0.0663 & $0.248^{*}$ & 0.784 \\
\hline \multirow{2}{*}{$\begin{array}{l}\text { Product and } \\
\text { service } \\
\text { innovation }\end{array}$} & Innovation input & 0.0695 & 0.0697 & 0.539 & 0.755 \\
\hline & Innovation frequency & 0.0650 & 0.0649 & 0.420 & 0.768 \\
\hline \multirow{6}{*}{$\begin{array}{l}\text { Resource } \\
\text { allocation }\end{array}$} & Natural resources & 0.0677 & 0.0682 & 0.388 & 0.776 \\
\hline & Customer resources & 0.0819 & 0.0812 & $0.192 *$ & 0.782 \\
\hline & Governmental resources & 0.0622 & 0.0630 & 0.675 & 0.738 \\
\hline & Cooperation capacity & 0.0750 & 0.0749 & 0.507 & 0.763 \\
\hline & Information system resources & 0.0709 & 0.0711 & 0.427 & 0.766 \\
\hline & Internal staff & 0.0737 & 0.0736 & 0.381 & 0.770 \\
\hline \multirow{4}{*}{$\begin{array}{c}\text { Service } \\
\text { performance }\end{array}$} & Use expectation & 0.0759 & 0.0754 & $0.195^{*}$ & 0.784 \\
\hline & Performance expectation & 0.0750 & 0.0747 & 0.301 & 0.776 \\
\hline & Community influence & 0.0677 & 0.0681 & 0.477 & 0.761 \\
\hline & Facilitating conditions & 0.0718 & 0.0717 & 0.388 & 0.770 \\
\hline \multicolumn{2}{|c|}{ Other reference indicators } & $\begin{array}{l}\mathrm{CI}=0.0000007 \\
\mathrm{CR}=0.0000004\end{array}$ & & \multicolumn{2}{|c|}{$\begin{array}{l}\text { Reliability (Cronbach`s } \alpha \text { ) } 0.782 \\
\text { KMO measure } 0.461 \\
\text { Bartlett test of sphercity sig. } 0.000\end{array}$} \\
\hline
\end{tabular}

Domestic research focused on the tourism value chain, while ignoring hidden factors that is the survival of the tourism economy, such as the natural environment, government policies and enterprise internal. Ni Juan (2005) believes apart from network externality, increasing returns, obvious monopoly, differentiated pricing, dynamic trading, lock-in principle and other economic characteristics of the network, the influence of e-commence on profitability of enterprise also comprises changes in competition structure in network environment and profit-seeking of enterprises. Liang Feng (2012) concludes that factors influencing profit of ecommerce are mainly target customers, customer value, value chain and core competencies 
through analysis on Taobao (www.taobao.com), the famous e-commerce enterprise in China. There have a great amount of in-depth researches about Chinese tourism, but it is still been ignored by the tourism enterprises and their managers. And then thousands and thousands of tourist complaints come up per year.

\subsection{China's Tourism Enterprise Managers' Misunderstanding}

Some obvious phenomenon is list from the deleted item above (see Table 4). The market of Chinese tourism is so huge that the enterprises don't need to segment the market, that's why the "growth property" and "market orientation" are ignored in the enterprise performance dimensions. Numbers of customers are so plentiful that most of the tourism products have its audiences even they are essentially the same tourism products. And that is the reason why corporate management of Chinese tourism enterprises don't need "innovation resource" too. Innovation resource means of enhancing operating cost and long profit period not as good as simply imitation. And they do not care the "natural resources" and "governmental resources", so there are only profits in their eyes. They can change the tour program whenever one sight are destroyed, and they also can design another tour products to escape the governments' rules although the nature of these tour products are both illegal. And "enterprise strategy" and "related industry services" have been deleted just because of the rapid profits of the tourism market, which leading to the quality of serve is rather spotty and the tour complaints occur frequently. It can be seen that Chinese tourism managements pay attention to short-term interests rather than long-term planning.

\section{Discussion and Conclusions}

(1) Construction of the scale is finished by the following steps: firstly, refer to a large number of literature review, learn as much as possible mature theories and previous research results. The informal scale of CFS on tourism industry profitability in e-commerce environment is designed combining with objective and theoretical framework of this study. After rigorous theoretical analysis and discussion with experts, the questionnaire scale has gone through repeated tests and modifications. Purify the items of questionnaire and scale by deleting 5 items of critical success factors on tourism industry profitability in e-commerce environment from originally 4 dimensions and 19 items. And a scale with high representativeness is finalized at last.

(2) AHP, GEM and CITC are frequently-used scale testing methods which are used in this paper. From the output result of this research, AHP and GEM have low requirements on the total sample quantity. Both of the output results are closer, and judgment results are consistent. But CITC has higher requirements on the total quantity of samples, and the outputs are more stringent. Each test method has some merits but also certain limitation.

(3) Experts participating in the research on critical factors ranges from the management of tourism e-commerce enterprises to government tourism management departments, as well as important enterprises closely linked with tourism e-commerce (banks, group purchase websites of tourism products and services and professional tourism institutions), avoiding the simplification and limitations of academic views, and providing a new thought for more objectively, accurately positioning the critical factors.

\section{Limitations and Future Research}

Successful model must be legitimate (supported by the government and systems, etc.,). In future research, with the help of the CSFs for China's tourism industry in e-commerce 
environment in this study, the tourism enterprise services and profits spiral escalation in ecommerce environment will be deeply analyzing and discussing.

\section{Acknowledgments}

This research was funded by a research grant from the National Natural Science Foundation of China (Grant No.71240023), Soft Science Project supported by Henan Science and Technology Agency (Grant No.102400450325), and Innovation Team of Philosophy and Social Science of Henan Colleges and Universities (Grant No.2012-CXTD-12).

\section{References}

[1] Q. Su and B. Lin, "Classification of Residents in the Tourist Attractions Based on Attitudes and Behaviors: A Case Studying”, Xidi, Zhouzhuang and Jiuhua Mountain, Geographical Research, vol. 1, no. 23, (2004).

[2] D. Gursoy, C. Jurowski and M. Uysal, "Resident Attitudes: A Structural Modeling Approach", Annals of Tourism Research, vol. 1, no. 29, (2002).

[3] H. Li, "Some Basic Concepts of Tourism Promotion_ A Speech at National Seminar on Tourism Bureau", Tourism Tribune, vol. 3, (1988).

[4] V. C. S. Heung, "Barriers to implementing e-commerce in the travel industry: a practical perspective", International Journal of Hospitality Management, vol. 22, (2003).

[5] F. Qiu, "Research on Travel Decision-making in Psychological Paradigm", Doctoral Dissertation of East China Normal University, vol. 4, (2004).

[6] C. Wang, B. Wen and C. Jiang, "Service Quality, Consumption Value, Customer Satisfaction and Behavioral Intention", Nankai Business Review, vol. 12, (2001).

[7] C. Cen and X. Gan, "Research on Customer Participation in Self-service Technology Environment and its Influential Factors", Forecast, vol. 2, no. 30, (2011).

[8] B. Senga, S. Jean and D. Siobhan, "Are hotels serving quality? An exploratory study of service quality in the Scottish hotel sector", Tourism Management, vol. 4, no. 28, (2007).

[9] L. Wang, F. Zhang and C. Li, "Quantitative Methods for Measuring Contribution Degree of Tourism to Regional Economic Development and its Application”, Systems Engineering Theory and Practice, vol. 5, (2006).

[10] M. Oppermann, “Tourism Destination Loyalty”, Journal of Travel Research, vol. 1, no. 39, (2000).

[11] J. F. Petrick, "Are loyal visitors desired visitors?", Tourism Management, vol. 4, no. 25, (2004).

[12] B. Wang and C. Wu, "Empirical Research on Influence of Scenic Region on Tourists' Loyalty", Management Review, vol. 11, (2011).

[13] H. Peng, "Causes and Countermeasures for Detaching of Management Research and Practice", Management Review, vol. 2, no. 23, (2011).

[14] R. L. Nolan, "Managing the Computer Resources: A Stage Hypothesis", Communication of the ACM (1973), pp. 399-403.

[15] C. Dellarocas, X. Q. Zhang and N. F. Awad, "Exploring the value of on line product reviews in forecasting sales: The case of motion pictures", Journal of Interactive Marketing, vol. 4, no. 21, (2007).

[16] R. Ahluwalia, R. E. Burnkrant and H. R. Unnava, "Consumer response to negative publicity: The moderating role of commitment. Journal of Marketing Research, vol. 2, no. 37, (2000).

[17] X. Guan, "Worthy Experience of Japanese and South Korean Government Promoting Innovation by Purchasing and Supporting SMEs", China Economic \& Trade Herald, vol. 10, (2013).

[18] D. Li, "Innovation of Business Model based on Structural Characteristics: Path Type, Industry Effect and Strategy System", China Soft Science, vol. 11, (2006).

[19] M. E. Porter, "How Competitive Forces Shape Strategy", Harvard Business Review, vol. 4, (1979).

[20] V. Venkatesh, M. G. Morris, G. B. Davis and F. D. Davis, "User Acceptance of Information Technology: Toward a Unified View", MIS Quarterly, vol. 3, no. 27, (2003).

[21] R. T. Rust, A. J. Zahorik and T. L. Keiningham, "Return on quality: making service quality financially accountable", Journal of Marketing, vol. 4, no. 59, (1995).

[22] A. V. Roth and W. E. Jackson, "Strategic determinants of service quality and performance: evidence from the banking industry", Management Science, vol. 11, (1995).

[23] Horng, J.-S. and C.-T. Tsai, "Government websites for promoting East Asian culinary tourism: A crossnational analysis", Tourism Management, vol. 1, no. 31, (2010). 


\section{Authors}

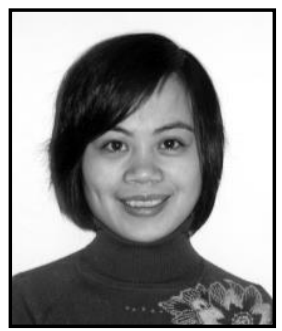

Yingmei Wei is a $\mathrm{PhD}$ candidate in the School of Management, Harbin Institute of Technology, Harbin, China, and a senior statistician in Zhongyuan University of Technology, Zhengzhou, China. Her research interests include sustainable tourism, tourism trust, tourism resource management and the impacts of culture change on policy and planning for tourism government.

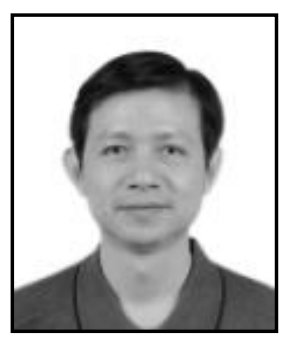

Runsheng Fang, Ph.D is a Professor in Henan University of Economics and Law, Zhengzhou, China. He has research interests in service management, resource management and enterprise management. And he is the leader of several National Natural Science Foundations of China.

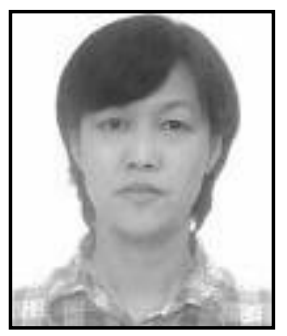

Yuqiang Feng, Ph.D is a Professor in the School of Management, Harbin Institute of Technology, Harbin, China, Her research interests include empirical research, case analysis and behavioral science in management and information system. She has published widely in European Journal of Information Systems and Computers in Human Behavior. 